\title{
LOW LEVEL PRESENCE OF GMO IN MALAYSIA'S IMPORT: THE ALTERNATIVE TOLERANCE AND ITS ECONOMIC EFFECTS
}

\author{
ISMAIL NORMAZ WANA*1, ANDREW JOHNNY² AND KAMARULZAMAN NITTY \\ HIRAWATY*3
}

${ }^{1}$ School of Business and Economics, ${ }^{2}$ Institute of Agricultural and Food Policy Studies, ${ }^{3}$ Department of Agribusiness and Bioresource Economics, Faculty of Agriculture, Universiti Putra Malaysia, 43400 UPM Serdang, Selangor, Malaysia.

*Corresponding author: nwi@upm.edu.my

Submitted final draft: 1 May $2020 \quad$ Accepted: 2 June 2020

http://doi.org/10.46754/jssm.2021.06.014

\begin{abstract}
The commercial use of genetically modified organisms (GMO) is increasing in both developed and developing countries. Problems with the sale of GMO in international trade are also increasing given the diverse regulatory frameworks needed to ship GMO products globally. One of the problems is the asynchronous authorisation which has led to low level presence (LLP) of unauthorised genetically modified (GM) material in imported food and feed products. Under the current regulations in Malaysia, the presence of an unauthorised GMO in the marketplace is regarded as a regulatory non-compliance to which the Malaysian government has a zero-tolerance approach. The objective of this paper is to assess the economic effects of alternative LLP tolerances for unauthorised GMO products. The study is modelled on the economic effects of different management options for LLP situations based on tolerance levels. The study first developed an analytical model and from the data collected, simulations of effects under different scenarios; which a zero-tolerance LLP and a non-zero tolerance LLP were performed. The study found that Malaysia can benefit economically from adopting non-zero tolerance LLP approaches, especially given that a yearly average of four million metric tonnes of imported corn and soybeans could potentially be subject to trade disruption.
\end{abstract}

Keywords: Genetically modified organism, sustainability, low level presence, zero tolerance, welfare effects.

\section{Introduction}

The commercial use of genetically modified organisms (GMO) is increasing in both developed and developing countries. In 2018, 191.7 million hectares of GM crops (up from 189.8 million hectares in 2017) were grown by a total of 17 million farmers in 26 countries, of which 21 were developing countries and 5 industrial countries. The main GM crop was soybean which accounts for $50 \%$ of the global GM crop area followed by corn $(30.7 \%)$, cotton $(13 \%)$, and canola $(5.3 \%)$. Herbicide tolerance has been the dominant trait of such GMO crops $(46 \%)$, while stacked traits accounted for $42 \%$ of the global GM crop hectarage (ISAAA, 2018).

Since its first introduction for commercial cultivation in 1996, many countries have adopted a domestic regulatory framework that deals with the requirement for authorisation of the use of GM crops (Adenle et al., 2013). Most of these countries impose conditions for domestic authorisation that involve an environmental risk or safety assessment before such crop is allowed to be commercialized or released into the environment (Brookes, 2008). Risk assessment procedures which the decision for authorisation will be based upon, are usually formulated in accordance with established guidelines produced by international bodies. In general, authorisations for commercialisation in every country happen individually at different timings (Smart et al., 2016). A distinction is commonly made between the purpose of the GM crop, that is whether it is intended for restricted use or to be released into the environment. Moreover, countries also make a difference between cultivating GM crop or applying it to the food and feed chain (Broeders et al., 2012), for example, raw or processed material. 
Thus, at any time, there is a possibility that GM crop authorised in one country for cultivation or food and feed purposes, is yet to be authorised in other countries with which the country that has given authorisation trades agricultural commodities (Kalaitzandonakes, 2011). This is commonly known as asynchronous authorisation. Asynchronous authorisation can happen because the time taken for the approval process is different from one country to another or it may occur due to approval never having been submitted to or given by the countries that are involved in the import of agricultural commodities (Clapp, 2008). When trace amounts of this unauthorised GM crops are detected in grain or seed shipments, or in ingredients or finished food products, it can lead to trade disruptions if the importing country applies a zero-tolerance approach and rejects the shipments. From a trade perspective, this situation is called low level presence (LLP).

The rejection may result in costly fines, lost revenue on the total grain shipment, expensive testing, and clean-up, unsold or destroyed grain or seed, product recalls in importing countries and the loss of export market share as the importing country sources grain from another country (Stein \& Rodríguez-Cerezo, 2010).

This paper attempts to assess the economic effects of alternative LLP tolerances for unauthorised GM crops in Malaysia. The next section provides a brief background about GMO crops and GMO regulations in Malaysia including zero-tolerance approach. Following that, the paper discusses the studies that have been conducted, its findings and analysis.

\section{Background}

\section{Regulatory Framework for GM Crops}

Demeke et al. (2006) regarded the Cartagena Protocol on Biosafety (CPB) which was adopted under the aegis of the United Nation's Convention on Biological Diversity (CBD) as central to the issues related with asynchronous approvals and LLP. The CPB encourages its members to make decisions on the import of
GMO crops and products for release into the environment, in accordance with scientifically accepted risk assessments. The CPB also establishes methodological steps and points to be taken into account while carrying out the risk assessment as well as monitoring and enforcement mechanisms to guarantee the safety of GMOs once they are approved.

Malaysia ratified the $\mathrm{CPB}$ in September 2003 and since then has taken steps to ensure a domestic regulatory framework on biosafety was put in place. Subsequently, the Malaysian Biosafety Act was approved by the Parliament in 2007. The Act is drafted to be in line with national policies on biodiversity and biotechnology and covers only modern biotechnology activities. It is neither against modern biotechnology nor pro modern biotechnology but it works as an enabling piece of legislation to ensure the safety of all GMO applications (Arujanan \& Singaram, 2018). The purpose of the Act is not only to protect human health but plant and animal health and the environment and biodiversity. The act regulates the release, importation and contained use of GMOs including its products.

The Act came into force on 1st December 2009 and was quickly followed by the Biosafety (Approval and Notification) Regulations 2010 on $1^{\text {st }}$ November 2010 to implement the Act. The Act and regulations represent a new regulatory system specifically to govern GMOs and its products and fulfil Malaysia's obligation under the $\mathrm{CPB}$.

The nature of the biosafety institutional framework diverges from one country to another country. Malaysia is operationalizing a centralized institutional framework whereby a single department is assigned to handle all the applications, provide administrative support for the risk assessment and decision making processes including organizing inputs from relevant agencies and public. Some countries have placed administrative responsibilities for biosafety in various government departments depending on the type or intended use of the GMOs in question (Andrew et al., 2018). 


\section{Authorized GMOs in Malaysia}

Under the Malaysian Biosafety Act, release activities mean any intentional introduction or release of GMOs and its products into the environment. These activities include supply or offer to supply for sale or placing on the market. Any application for authorisation for release activities including importation of GMOs must be submitted to the National Biosafety Board (NBB) together with the prescribed fees. The NBB, after having considered the recommendations of the scientific body and the comments from relevant government agencies as well as the public, will make a decision on whether to grant approval to the application. The authorisation process takes a maximum of 180 working days to be completed (Ramatha, 2011). As shown in Table 1, Malaysia has approved $30 \mathrm{GM}$ events for corn and soybeans for the purpose of food, feed, and processing up to 2018. The number of approvals granted is still low if compared to those of its key trading partners.

Malaysia imports around three million metric tonnes of corn and 500 thousand metric tonnes of soybeans annually. The origins of these products are mostly from the United States, Brazil, and Argentina, which are among the top producers of corn and soybeans in the world. About $80 \%$ of corn and soybeans cultivated in these countries are genetically modified (refer to Table 2).

Given current import trends and the status of GM product approvals, Malaysia must not rule out the possibility of unauthorised GM corn or soybeans being present in the local market.

\section{Zero Tolerance Policy}

Countries are diverging when it comes to strategies used to address LLP issues. These strategies can be no specific LLP policy, zero tolerance or technical zero policies, or a policy with a low threshold for LLP. Generally, a zero-tolerance policy or approach implies that ingredient or component for any import of food or feed products cannot contain even trace amounts of GM materials for which authorisation has not been given by the importing country (Matsuo \& Yoshikura, 2014). In many countries, a zero-tolerance policy is applied when dealing with unauthorised GM crops in its territory. This statement is consistent with the result from the

Table 1: Approved GM events for corn and soybeans as of 2018

\begin{tabular}{lccccc}
\hline \multirow{2}{*}{ Type of crop } & Malaysia & Argentina & Brazil & Gey Trading Partners & USA \\
\cline { 3 - 5 } & 19 & 51 & 52 & 43 & 238 \\
\hline Corn & 11 & 17 & 18 & 25 & 41 \\
Soybeans & 30 & 68 & 70 & 68 & 279 \\
Total GM events & & &
\end{tabular}

Source: International Service for the Acquisition of Agri-biotech Applications (ISAAA, 2018).

Table 2: Exports of corn, soybean by GM producing countries to Malaysia, 2014 (metric tonne)

\begin{tabular}{lcccccr}
\hline \multirow{2}{*}{ Country } & \multicolumn{2}{c}{ Share in Global Production } & \multicolumn{2}{c}{ GM Share in Production } & \multicolumn{2}{c}{ Export to Malaysia } \\
\cline { 2 - 7 } & Corn & Soybean & Corn & Soybean & \multicolumn{1}{c}{ Corn } & \multicolumn{1}{c}{ Soybean } \\
\hline Argentina & $3.2 \%$ & $17.4 \%$ & $80 \%$ & $99 \%$ & $1,579,032$ & 43,124 \\
Brazil & $7.7 \%$ & $28.3 \%$ & $79 \%$ & $83 \%$ & $1,594,505$ & 62,482 \\
United States & $34.8 \%$ & $34.9 \%$ & $93 \%$ & $94 \%$ & 55,982 & 223,383 \\
Total & & & & $3,229,519$ & 328,989 \\
Share from Malaysia's total import 2014 & & & $84.5 \%$ & $57 \%$ \\
\hline
\end{tabular}

Source: FAOSTAT (2017), and Brookes and Barfoot (2017) 
survey conducted by the Food and Agriculture Organisation (FAO) in 2013, where 46 out of 64 countries took part in a survey (or $72 \%$ ) indicated that they will apply a zero-tolerance approach in the event of the LLP of GMO crops (Atici, 2014).

Malaysia together with several other developing countries at the moment does not have a dedicated policy to address unintended, low levels of unauthorised GM materials that could be found in imported grain, food, and feed products. The existing law in Malaysia has a zero-tolerance approach hence the presence of any unauthorised GM crop in the Malaysian marketplace is regarded as a regulatory noncompliance. In this regard, grain or seed shipments that contain even trace amounts of unauthorised GM crop product would be classified as a non-compliance and this will prompts a management strategy involving the removal of LLP of said GMO products. Based on Malaysia's response to the FAO survey (Atici, 2014), no incident of LLP has been recorded so far. Despite that, the concern remains about the practicality of a zero-tolerance approach in managing LLP situations.

From the trader's perspective, the use of a non-zero tolerance LLP policy is best (Ryan \& Smyth, 2012). However, this policy is only practical if it balances risks and other economic considerations (Marcoux et al., 2013)

\section{Materials and Method}

Gruère (2016) developed a model to assess the most important factors to consider when setting up LLP tolerance or threshold. He identified three factors that matter: the total surplus or market effects; the perceived safety or risk avoidance effect; and the cost of implementation.

However, there are few other assumptions applied to this type of analytical model. For instance, since Malaysia is a small country, it can be assumed to be a price taker on the international market. It is also assumed that there is a linear inverse demand for corn or soybean products in Malaysia, and a linear supply. From the perspective of regulatory authorities, as long as the shipments contain corn or soybean that originate from GM crop producing countries, the possibility of new GM crops entering domestic market and to cause safety concerns remain positive (Kalaitzandonakes et al., 2011). Finally, perfect or strict enforcement is assumed to be in place as a benchmark.

In modelling the framework, it is assumed that, Malaysia is importing corn or soybean products from a GM corn or soybean producing country, for example, Country A. At time $t_{l}$, a new GM corn or soybean event is authorised in Country A, but not yet in Malaysia. Argentina is also a country where GM corn or soybean is mixed in with other GM crop commodities. During the time regulatory process for approval takes place, say until time $t_{2}$, Malaysia has to look for a substitute or a different type of products, presumably a non-GM corn or soybean product, either in Country A or another country to meet its domestic demand.

For comparison purposes, let's say that Malaysia has to purchase the non-GM corn or soybean product at a price higher than the price of GM corn or soybean product purchased from Country A which has mixed GM crop commodities.

Rooted in the above framework, Malaysia, as an importing country, is expected to make a decision from a social welfare perspective based on the following formula -

$$
W=\left[\frac{(b-p) / Q}{2}+\frac{\left(c Q^{2}\right)}{2}\right]-[C S(\tau)+C T(\tau)+C O+C A] Q
$$

where $W$ denote basic welfare ; $b$ denote demand parameter; $c$ denote supply parameter; $p$ denote expected price under the existing policy; $Q$ denote quantity of products measured in kilogram (kg); CS denote cost of taking sample; $C T$ denote cost of GM testing; $C O$ denote staff related costs; $C A$ denote administrative related costs; and $\tau$ denote tolerance level. Total welfare, as expressed in the above formula, can be segregated into two sections: first, the Marshallian surplus; and second, the costs of regulation to the government. 
Total surplus is derived after the consumer surplus and producer surplus. However, since Malaysia does not produce corn and soybean for domestic consumption during the observed period, only estimation for the consumer surplus was included in the findings to represent the total surplus.

The expected price is one of the main components to compute the consumer surplus. In order to derive the expected price, the study computed for the price of the GM or mixed products, the price of non-GM products, the share of GM corn or soybean products in imports and the probability of rejection of shipments which is determined based on LLP tolerance level.

The total costs were estimated based on information provided by relevant government agencies that are directly involved in GMO monitoring and enforcement activities specifically to detect the presence of unauthorised GM events at five key entry points in Malaysia. In providing the information, the agencies concerned acknowledged the government current policy towards LLP situation (that is zero-tolerance approach) and limited resources they had (that include manpower, financial, equipment and technical capacity) to meet those needs. Therefore, the information has to take into account activities that have been done and what they were actually planning with the available resources.

A template has been prepared for this purpose as a guide for the agencies to provide the information. The template consists of six sections covering:

i) emolument costs related to LLP monitoring and enforcement activities;

ii) training expenses for the staff involved in the LLP monitoring and enforcement activities;

iii) costs for sampling, confiscation, and detection of GMO;

iv) costs for storage and disposal of GMO samples; v) costs for delivery and transportation for GMO samples; and

vi) other costs directly related to monitoring and enforcement of LLP.

$C S(\tau)$, which is the costs involved in taking the sample, correlated with the tolerance level since for a given concentration level, when the tolerance level is high, it does not require a large sample (Gruère, 2016).

$C T(\tau)$ represents the costs of testing, also depends on the tolerance level. It is assumed that when the tolerance level is low, the cost of testing becomes more expensive due to level of detection and analysis required or simply can be summarized as $C T(\tau<1 \%)>C T(1 \%<\tau<5 \%)$ $>C T(\tau>5 \%)$. For the testing costs, Gruère \& Rosegrant (2008) has provided an estimation of cost values that can be assigned to the tolerance level as follows: 5\% tolerance level for $\$ 0.1$ per tonne; $2.5 \%$ for $\$ 0.5$ per tonne; $1 \%$ and $0.9 \%$ for $\$ 1$ per tonne; $0.5 \%$ for $\$ 1.5$ per tonne, and $0.1 \%$ for $\$ 2.5$ per tonne.

\section{Results and Discussion}

The study analysed the global production of corn and soybean and determined the GM shares of these products in selected producer countries. The analysis also looked into the portion of GM or mixed products in corn and soybean imports to Malaysia. Figure 1 illustrates the composition based on the volume of imports of corn and soybean from the year 2010 to 2014 . For the purpose of this analysis, data on imports were segregated according to their source. The exporters can be GM producing countries or nonGM producing countries. Using the information on GM shares and volume of imports by Malaysia for corn and soybean products from individual GM producing country, GM portion of these imports can be determined. From the figure, it was estimated that the GM portion in imports of corn by Malaysia for the years 2010 to 2014 range between $57 \%$ and $66.1 \%$. Meanwhile, for soybean, the portion was estimated to be high, at more than $90 \%$ on average for the same period. These findings on the GM portion in Malaysia's 


\section{Corn}

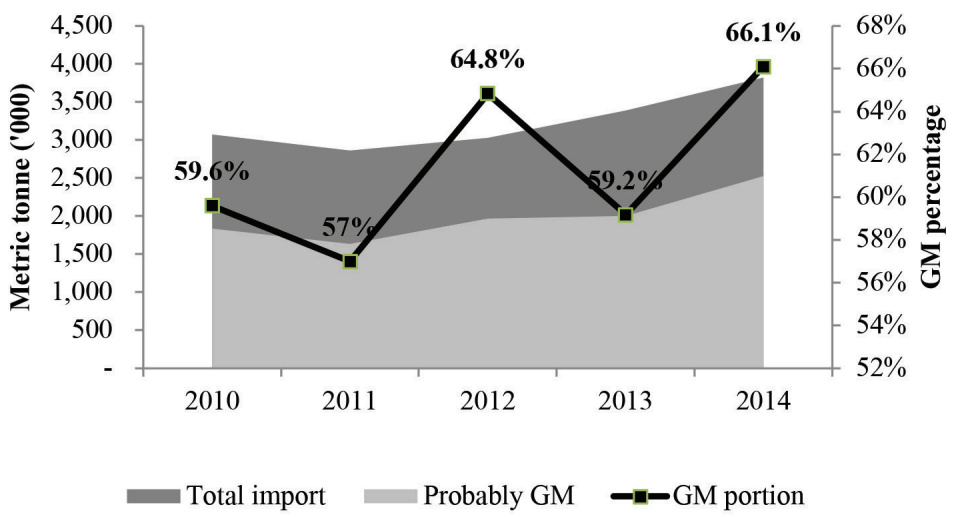

\section{Soybean}

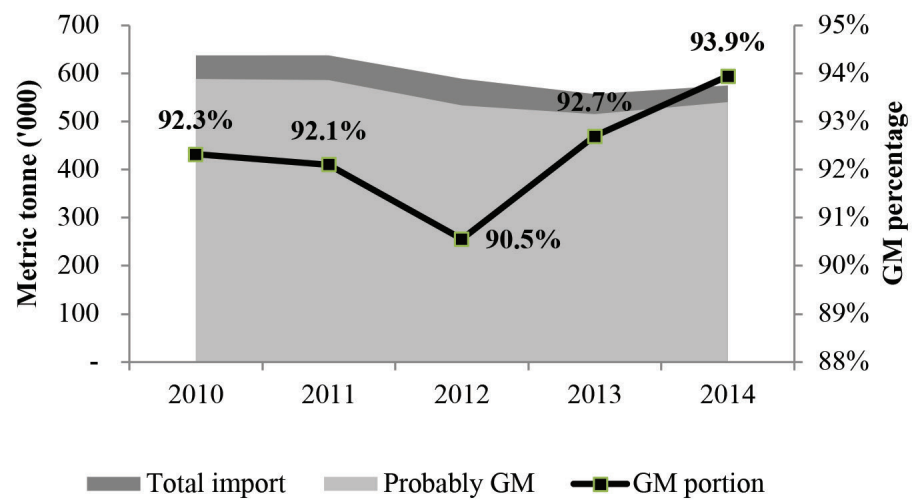

Figure 1: Non-GM versus likely GM in Malaysia's import for Corn and Soybean, 2010-2014

corn and soybean imports show that key GM corn and GM soybean producing countries were among Malaysia's major trading partner for these products.

The expected price per kilogram was computed for different LLP tolerance levels and then used to estimate the effects on consumer surplus. When LLP tolerance increased from $0 \%$ to $5 \%$, the expected price for corn reduced between $0.5 \%$ and $1.5 \%$ whereas, for soybean, it reduced between $0.1 \%$ and $0.4 \%$.

Variations in the expected price for corn and soybean from the year 2010 to 2014 were partly due to changes in the price premium or the difference between the price of GM and nonGM products over that period.

Table 3 shows the simulation results for the consumer surplus based on different LLP tolerance levels. The consumer surplus is derived after the difference between the price of the imported product and the expected price for the same product then multiplies with the volume of imports.

For corn, it can be interpreted that the consumer surplus will increase when the LLP tolerance level increases. In 2014 for example, the consumer surplus increased from US\$1.9 million to US $\$ 8.8$ million if LLP tolerance level 
is changed from $0 \%$ or zero-tolerance to $5 \%$. Likewise, the consumer surplus for soybean also increases with the increase of the LLP tolerance despite the negative surplus.

In Table 3, when the LLP tolerance increased from $0 \%$ to $5 \%$, the consumer surplus for soybean increased by $0.6 \%$ in 2014 . The consumer surplus for soybean is negative partly due to a higher expected price for soybean compared to the price of the imported product. The expected price can vary depending on the difference between the price of GM or mixed product and the price of non-GM product.

The cost incurred by the government for LLP related monitoring and enforcement activities under the existing LLP management framework was estimated at around US $\$ 180$ thousand per annum (Table 4). Slightly more than half $(58.9 \%)$ of the costs went to sampling, confiscation and detection activities.
These activities used more resources compare to the rest. Precise GMO testing and detection, for example only can be performed in the laboratory that is equipped with the latest equipment. About $30 \%$ of the total costs were allocated for staff emolument and training.

In determining the costs for emolument, details about the staff's monthly salary and hours spent on LLP related monitoring and enforcement activities were obtained. Other related costs include storage and disposal, transportation and rental fees.

All GMO samples need to be stored properly and disposed in accordance to the standard procedures. GMO samples need to be transported or delivered from the place where the sample was taken to the place where it will be kept before sending it to the laboratory for analysis. Although the costs were minimal, these activities are integral and part of the monitoring works to detect the presence of unauthorised GM crops.

Table 3: Consumer surplus based on different LLP tolerance

\begin{tabular}{cccccccccccc}
\hline \multirow{2}{*}{$\begin{array}{c}\text { LLP } \\
\text { Tolerance }\end{array}$} & \multicolumn{9}{c}{ Corn } & \multicolumn{8}{c}{ Consumer Surplus (in Million US\$) } \\
\cline { 2 - 12 } & $\mathbf{2 0 1 0}$ & $\mathbf{2 0 1 1}$ & $\mathbf{2 0 1 2}$ & $\mathbf{2 0 1 3}$ & $\mathbf{2 0 1 4}$ & $\mathbf{2 0 1 0}$ & $\mathbf{2 0 1 1}$ & $\mathbf{2 0 1 2}$ & $\mathbf{2 0 1 3}$ & $\mathbf{2 0 1 4}$ \\
\hline $0 \%$ & 38.1 & 34.3 & $(25.2)$ & 11.7 & 1.9 & 0.7 & $(27.5)$ & $(26.6)$ & $(23.8)$ & $(26.3)$ \\
$0.1 \%$ & 38.2 & 34.5 & $(25.2)$ & 12.0 & 2.1 & 0.8 & $(27.4)$ & $(26.5)$ & $(23.8)$ & $(26.3)$ \\
$0.5 \%$ & 38.7 & 35.1 & $(24.8)$ & 13.0 & 2.9 & 1.0 & $(27.1)$ & $(26.2)$ & $(23.4)$ & $(26.2)$ \\
$0.9 \%$ & 39.2 & 35.8 & $(24.4)$ & 14.1 & 3.8 & 1.3 & $(26.8)$ & $(25.9)$ & $(23.1)$ & $(26.1)$ \\
$1 \%$ & 39.3 & 36.0 & $(24.3)$ & 14.4 & 4.0 & 1.3 & $(26.8)$ & $(25.8)$ & $(23.1)$ & $(26.1)$ \\
$3 \%$ & 41.2 & 38.8 & $(22.8)$ & 19.0 & 7.7 & 2.4 & $(25.6)$ & $(24.6)$ & $(21.8)$ & $(25.8)$ \\
$5 \%$ & 41.8 & 39.7 & $(22.3)$ & 20.3 & 8.8 & 2.7 & $(25.2)$ & $(24.3)$ & $(21.4)$ & $(25.7)$ \\
\hline Difference & 3.7 & 5.4 & 2.9 & 8.7 & 6.9 & 2.0 & 2.3 & 2.3 & 2.4 & 0.6 \\
$(0 \%$ to 5\%) & & & & & & & & & & \\
\hline
\end{tabular}

Table 4: Estimated costs for GMO monitoring activities

\begin{tabular}{lcc}
\hline \multicolumn{1}{c}{ Activities } & Estimated cost (US\$) & Percentage \\
\hline Sampling and testing & 106,461 & $58.9 \%$ \\
Staff costs & 55,770 & $30.8 \%$ \\
Other related costs & 18,541 & $10.3 \%$ \\
\hline Total & 180,772 & $100 \%$ \\
\hline
\end{tabular}


The analyzed data on changes in the total surplus and costs incurred to monitor unauthorised GMO presence are the main elements to estimate the total welfare effects. The estimation results are expressed in total welfare under zero-tolerance approach and several non-zero LLP tolerance options.

Although the results do not claim to be precise estimates of the economic effects from the change in LLP tolerance level, but it can serve as a benchmark value in designing the threshold level for LLP management strategy in Malaysia. Table 5 shows the welfare effects for corn and soybean in the case of $0 \%, 0.1 \%, 0.5 \%$, $0.9 \%, 1 \%, 3 \%$ and $5 \%$ LLP tolerance levels. It demonstrates relatively consistent change in the total welfare when the tolerance levels increase from $0 \%$ to $1 \%$.

For corn, from zero-tolerance (or 0\% LLP) to $1 \%$ LLP tolerance, the total welfare is expected to increase from US\$12.05 million to US\$13.82 million per year whereas for soybeans, under the same scenario, the total welfare changed from -US\$20.78 million to -US\$20.13 million per year. Thus, the maximum change in the total welfare for a $1 \%$ change in LLP tolerance was $14.7 \%$ for corn and $3.1 \%$ for soybean.

The percentage change was higher if the tolerance levels increase further to $3 \%$ and $5 \%$. It can be observed that the change in total welfare for corn is $39.1 \%$ and $46.6 \%$ for the changes in LLP tolerances from $0 \%$ to $3 \%$ and from $0 \%$ to $5 \%$ respectively. The similar trend is also noticeable for soybean but with a smaller percentage value, $8.2 \%$ and $9.7 \%$ for LLP tolerances change to $3 \%$ and $5 \%$ respectively.

Figure 2 graphically presents the welfare change across scenarios as represented by the darker line. The line also demonstrates the change in total welfare at different LLP tolerances for the combined products. The comparison across scenarios shows that going from $0 \%$ to $5 \%$ tolerance increases the welfare by $87.4 \%$. In fact, when the tolerance level increased from $0 \%$ to $3 \%$, the welfare has changed notably by $73.3 \%$ or US $\$ 6.4$ million per year, a different of US\$1.23 million from 5\% tolerance.

The lighter line in the figure is representing the probability of rejection. The number which was adapted from Gruère (2009) explains the probability of the products get rejected by the importing countries under certain LLP tolerance measures as a precaution that the products might contain unauthorised GM materials. Under the GM-ban scenario, the probability of rejection can be as high as $100 \%$ depending on the origin of the imported products.

On the contrary, an all-pass scenario can minimise the probability of rejection as low as $0 \%$ subject to clearance by authorities in charge

Table 5: Welfare effects simulation (in million US\$)

\begin{tabular}{|c|c|c|c|c|c|c|c|c|}
\hline \multirow[t]{2}{*}{ Effect } & \multirow[t]{2}{*}{ Crop } & \multicolumn{7}{|c|}{ LLP tolerance } \\
\hline & & $0 \%$ & $0.1 \%$ & $0.5 \%$ & $0.9 \%$ & $1 \%$ & $3 \%$ & $5 \%$ \\
\hline \multirow[t]{2}{*}{ Surplus effect } & Corn & 12.14 & 12.32 & 13.00 & 13.69 & 13.86 & 16.78 & 17.67 \\
\hline & Soybean & (20.69) & (20.63) & (20.39) & (20.15) & (20.09) & (19.07) & (18.76) \\
\hline \multirow{2}{*}{$\begin{array}{l}\text { Cost of } \\
\text { implementation }\end{array}$} & Corn & 0.093 & 0.093 & 0.058 & 0.040 & 0.040 & 0.022 & 0.007 \\
\hline & Soybean & 0.087 & 0.087 & 0.054 & 0.037 & 0.037 & 0.020 & 0.007 \\
\hline \multirow{4}{*}{$\begin{array}{l}\text { Total welfare } \\
\text { change }\end{array}$} & Corn & 12.05 & 12.22 & 12.94 & 13.65 & 13.82 & 16.76 & 17.66 \\
\hline & $\begin{array}{l}\% \text { change } \\
\text { from } 0 \%\end{array}$ & & $1.4 \%$ & $7.4 \%$ & $13.3 \%$ & $14.7 \%$ & $39.1 \%$ & $46.6 \%$ \\
\hline & Soybean & (20.78) & (20.72) & (20.45) & (20.19) & (20.13) & (19.09) & (18.76) \\
\hline & $\begin{array}{l}\% \text { change } \\
\text { from } 0 \%\end{array}$ & & $0.3 \%$ & $1.6 \%$ & $2.8 \%$ & $3.1 \%$ & $8.2 \%$ & $9.7 \%$ \\
\hline
\end{tabular}




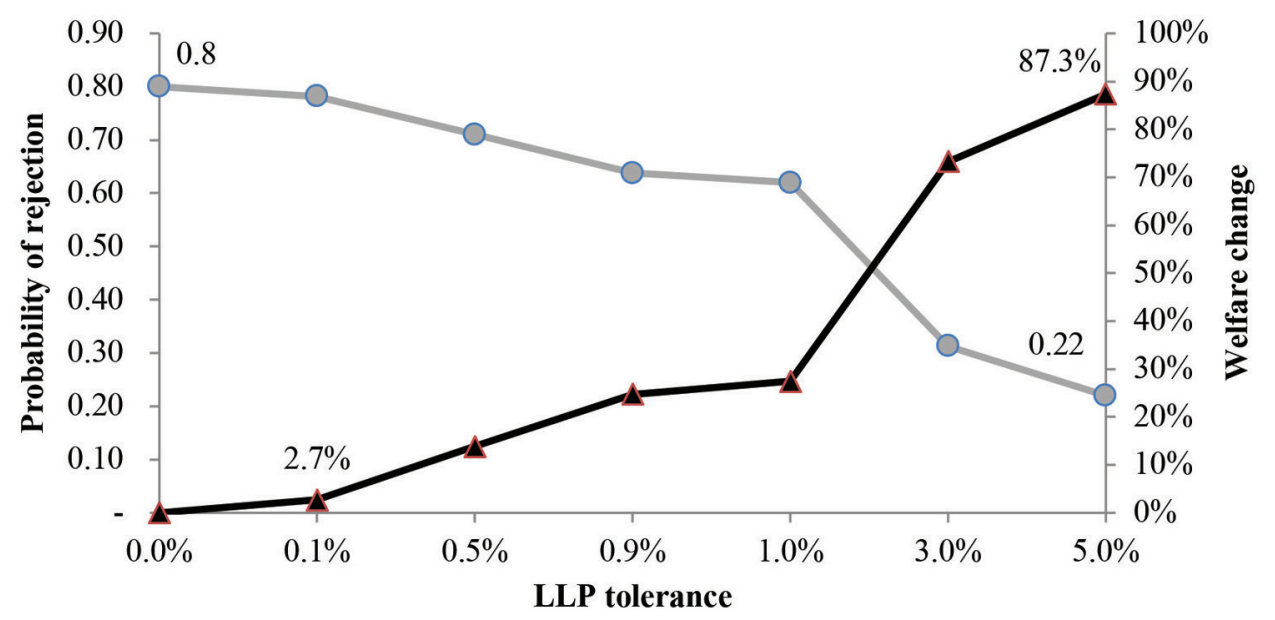

-0 -Probability of rejection $\quad-\Delta-$ Welfare change from zero tolerance

of laws pertaining to the products. In between of these two scenarios, a country can choose to regulate the use of GMO and either to tolerate or not to tolerate an LLP situation.

If the country decides to tolerate, the selection of tolerance level will have an impact on the probability of rejection. In Figure 2, it shows how the probability of rejection corresponds to LLP tolerance. The probability that the products get rejected going down from 0.8 to 0.22 when LLP tolerance increases from $0 \%$ to $5 \%$. The same pattern in the welfare change also observed in the probability of rejection when it drops drastically from 0.62 to 0.31 as the tolerance level increase from $1 \%$ to $3 \%$.

\section{Conclusion}

The increasing trend of GM crops commercialization can translate into more GM crop products being imported into Malaysia. Concerns always arise on the authorisation status of these GM crop products in Malaysia. In practical, it is difficult to completely prevent LLP incidents from happening although best management practices are strictly followed. Considering Malaysia is an importer of corn and soybean products from major GM producing countries, the application of a zero-tolerance approach for LLP may need a review in term of its practicality.

Regardless of the LLP management options, the presence of an unauthorised GM product can have significant economic costs. For instance, the study showed that the choice of LLP tolerance significantly affects cost and welfare. Thus, the question for decision makers is whether the risk prevention associated with zero-tolerance is worth the potential additional cost in an LLP situation in this case. This means that the choice of zero tolerance over non-zero tolerance level is justified if regulators believe that the risk value of imports of maize or soybean supplies with 5\% LLP of unauthorised GM materials increases significantly compared with a zero-tolerance for LLP.

Although it is not possible to reach final conclusions without comprehensive information that illustrates the risk of using GMOs, the discussion in this document implies that there is a substantial likelihood for risk aversion in society to reduce or abolish the benefits of using GMOs for others. With a view that different countries at diverse phases of development have different priorities regarding the risks associated with an increase in welfare, the ability of one country to dictate the ability of another country to benefit from the use of GMOs may lead to a decrease in potential welfare gains. 
If minimizing delays in the regulatory process and maximizing trust unambiguously increases overall welfare, choosing a tolerance level will balance perceived risks and costs, and should be chosen based on local circumstances.

\section{Acknowledgements}

We would like to take the opportunity to officers that participate during data collection especially to Department of Biosafety, Ministry of Natural Resources and Environment, Ministry of Health - National Public Health Laboratory, Ministry of Health - Food Safety and Quality Division, Malaysian Quarantine and Inspection Services, and Department of Chemistry. We extend the acknowledgement to University Putra Malaysia for funding our research under Grant Putra UPM (GP-IPS/2016/9510200).

\section{References}

Adenle, A. A, Morris, E. J., \& Parayil, G. (2013). Status of development, regulation and adoption of GM agriculture in Africa: Views and positions of stakeholder groups. Food Policy, 43, 159-166.

Andrew, J., Ismail, N. W., \& Djama, M. (2018). An overview of genetically modified crop governance, issues and challenges in Malaysia. Journal of the Science of Food and Agriculture, 98, 12-17.

Arujanan, M., \& Singaram, M. (2018). The biotechnology and bioeconomy landscape in Malaysia. New Biotechnology, 40, 52-59.

Atici, C. (2014). Low levels of genetically modified crops in international food and feed trade: Food and Agriculture Organization (FAO) international survey and economic analysis. FAO Commodity and Trade Policy Research Working Paper, 44(44).

Backus, G. B. C., Berkholt, P., Eaton, D. J. F., Franke, L., de Kleijn, A. J., Lotz, B., van Mil, E. M., Roza, P., \& Uffelmann, W. (2008). EU policy on GMOs: A quick scan of the economic consequences. Report 2008-070, LEI Wageningen UR, The Hague.
Broeders, S. R. M., De Keersmaecker, S. C. J., \& Roosens, N. H. C. (2012). How to deal with the upcoming challenges in Genetically Modified Organism (GMO) detection in food and feed. Journal of Biomedicine and Biotechnology, 2012, 1-12. https://doi. org/10.1155/2012/402418

Brookes, G. (2008). Economic impacts of low level presence of not yet approved $G M O s$ on the EU food sector. Report Commissioned by European Trade and Industry Organizations, (May).

Brookes, G., \& Barfoot, P. (2017). GM Crops: Global Socio-Economic and Environmental Impacts 1996-2015. UK: PG Economics Ltd. (June).

Bullock, D. S., \&Desquilbet, M. (2002). The economics of non-GMO segregation and identity preservation. Food Policy, 27(1), 81-99.

Clapp, J. (2008). Illegal Genetically Modified Organism (GMO) releases and corporate responsibility: Questioning the effectiveness of voluntary measures. Ecological Economics, 66, 348-358.

Demeke, T., Perry, D. J., \& Scowcroft, W. R. (2006). Adventitious presence of Genetically Modified Organisms (GMOs): Scientific overview for Canadian grains. Canadian Journal of Plant Science, 86(1), $1-23$.

Food and Agriculture Organization Corporate Statistical Database (FAOSTAT). (2017). Trade Data - Crops and livestock products. Retrieved on August 21, 2017 from FAOSTAT Website: http://www.fao.org/ faostat/en/\#data

Fulton, M., \& Giannakas, K. (2004). Inserting GM products into the food chain: The market and welfare effects of different labelling and regulatory regimes. American Journal of Agricultural Economic, 86(14108), 42-60.

Gruère, G. P. (2009). Asynchronous approvals of GM products, price inflation, and the Codex 
Annex: What low level presence policy for APEC countries? Paper presented at the International Agricultural Trade Research Consortium Analytic Symposium, June 2223, 2009, Seattle, Washington.

Gruère, G. P. (2016). Chapter 22 - Asynchronous approvals and the low level presence of unapproved GM products in imports: How "tolerant" should small countries be? In N. Kalaitzandonakes, P. W. B. Phillips, \& S. Smyth (Eds.), The Coexistence of Genetically Modified, Organic and Conventional Foods: Government Policies and Market Practices, Natural Resource Management and Policy Series ( Pp. 297309). New York: Springer.

Gruere, G. P., \& M. W. Rosegrant. (2008). Assessing the implementation of the Biosafety Protocol's proposed stringent information requirements on countries of the Asia Pacific Economic Cooperation. Review of Agricultural Economics, 30(2), 214-232

Hobbs, J. E., Kerr, W. A., \& Smyth, S. J. (2013). How low can you go? The consequences of zero tolerance. AgBioForum, 16(3), 207221.

Hobbs, J. E., Kerr, W. A., \& Smyth, S. J. (2014). The perils of zero tolerance: Technology management, supply chains and thwarted globalisation. International Journal of Technology and Globalisation, 7(3), 203.

International Service for the Acquisition of Agribiotech Applications (ISAAA). (2018). GM approval database - Approved GM events by country. Retrieved on April 19, 2020 from ISAAA Website: http://www.isaaa. org/ gmapprovaldatabase/default.asp

Kalaitzandonakes, N. (2011). The economic impacts of asynchronous authorisation $s$ and low-level presence: An overview. International Food \& Agricultural Trade Policy Council Position Paper, (October), 22.
Kalaitzandonakes, B. N., Kaufman, J., \& Miller, D. (2011). Potential economic impacts of asynchronous approvals of biotech crops on Latin American countries. International Food \& Agricultural Trade Policy Council Discussion Paper, (October).

Kalaitzandonakes, N., Kaufman, J., \& Miller, D. (2014). Potential economic impacts of zero thresholds for unapproved genetically modified organisms (GMOs): The European Union (EU) case. Food Policy, 45, 146-157.

Kalaitzandonakes, N., Lusk, J., \& Magnier, A. (2018). The price of non-genetically modified (non-GM) food. Food Policy, 78, 38-50.

Landmark Europe. (2009). The cost of lowlevel presence of GMOs in food products in Europe. Brussels: Landmark Public Policy Advisers Europe.

Marcoux, J. M., Gomez, O. C. C., \& Létourneau, L. (2013). The inclusion of non-safety criteria within the regulatory framework of agricultural biotechnology: Exploring factors that are likely to influence policy transfer. Review of Policy Research 30(6): 657-684.

Matsuo, M., \&Yoshikura, H. (2014). "Zero" in terms of food policy and risk perception. Food Policy, 45, 132-137.

Ramatha, L. (2011). Administrative systems for handling biosafety issues in Malaysia. Biosafety Protocol News, 9, 12-13. Retrieved on January 20, 2018 from Biosafety Clearing House Website: https:// bch.cbd.int/protocol/ cpb newsletter.shtml

Ryan, C. D., \& Smyth, S. J. (2012). Economic implications of low-level presence in a zerotolerance European import market: The case of Canadian Triffid Flax. AgBioForum, 15(1), 21-30.

Smart, R., Blum, M., \& Wesseler, J. (2016). Trends in approval times for genetically engineered crops in the United States and the European Union. Journal of Agricultural Economics, 68, 182-198. 
Stein, A. J., \& Rodríguez-Cerezo, E. (2010). Wilson, N. L. W., \& Worosz, M. R. (2014). Zero Low-level presence of new genetically modified (GM) crops: An issue on the rise tolerance rules in food safety and quality. for countries where they lack approval. Food Policy, 45, 112-115.

AgBioForum, 13(2), 173-182. 